\title{
EDITORIAL
}

\section{Emergencia del síndrome cardiopulmonar por hantavirus en las Américas}

\author{
GREGORY J. MERTZ, ${ }^{1}$ PABLO A. VIAL ${ }^{2}$

\begin{abstract}
EMERGENCE OF HANTAVIRUS CARDIOPULMONARY SYNDROME IN THE AMERICAS
\end{abstract}

El hantavirus se reconoció por primera vez en 1993 como el agente causal de una enfermedad severa en seres humanos en América. En mayo de 1993, en el Sur-Oeste de los Estados Unidos de Norte América (E.U.A.), se observó la aparición de un número inusual de casos de lo que parecía una enfermedad desconocida en adultos jóvenes, caracterizada por un pródromo de fiebre, seguido de un rápido desarrollo de edema pulmonar, derrame pleural, e insuficiencia respiratoria, asociados a trombocitopenia y leucocitosis y, en casos severos, acidosis láctica, colapso cardiovascular y muerte. ${ }^{I}$ Investigadores del Centro de Control de Enfermedades en Atlanta, Georgia (U.S. Centers for Disease Control and Prevention - CDC) analizaron muestras de suero obtenidas de estos pacientes y observaron que presentaban una reacción serológica positiva contra un grupo de virus conocidos como patógenos humanos, denominados hantavirus, incluido el prototipo hantavirus, que causa la fiebre hemorrágica con síndrome renal (FHSR) en Asia. Este hallazgo fue seguido por la detección de ARN de hantavirus por técnica de transcripción reversa y reacción de polimerasa en cadena (TT-RPC) en tejidos obtenidos en las autopsias de los casos fatales y de muestras de células mononucleares de sangre periférica obtenidas de pacientes durante la fase aguda de la enfermedad, ${ }^{2}$ así como de roedores (Peromyscus maniculatus) cazados en trampas puestas en el área geográfica donde ocurría el brote. ${ }^{3}$ Posteriormente varios laboratorios aislaron un hantavirus hasta entonces desconocido, al que se denominó virus Sin Nombre, en el roedor conocido como deer mouse o ratón venado (P. maniculatus $)^{4}$ y mediante secuenciación del genoma viral se estableció la relación genética existente entre los virus que infectan a roedores y humanos. ${ }^{5}$ El síndrome clínico asociado con el virus en América se denominó inicialmente síndrome pulmonar por hantavirus (SPH). El roedor $\boldsymbol{P}$. maniculatus tiene una amplia distribución a lo largo de casi todo el territorio de Norte América, y el virus Sin Nombre se ha reconocido como la causa de la mayoría de los 270 casos notificados en E.U.A. hasta el 12 de septiembre del 2000.

1 Department of Internal Medicine, University of New Mexico Health Sciences Center, Albuquerque, New Mexico, USA;

2 Departamento de Pediatría y Centro de Investigaciones Médicas, Facultad de Medicina, Pontificia Universidad Católica de Chile

Este artículo contó con el apoyo de un Proyecto de U.S. Public Health Service, número AI45452 and TW01133 
Emergencia del síndrome cardiopulmonar por hantavirus en las Américas - G. J. Mertz y P. A. Vial C.

Poco tiempo después del descubrimiento del virus Sin Nombre, se notificaron casos de SPH y nuevas especies de hantavirus fueron descritas a lo largo de todo el continente americano, habiéndose confirmado casos en Argentina ${ }^{6-9}$ Brasil, ${ }^{10}$ Canadá, ${ }^{11}$ Chile,${ }^{8,12,13}$ Panamá, ${ }^{14}$ Paraguay ${ }^{15,16}$ y Uruguay. ${ }^{11}$ En estos países se han identificado nuevas especies de hantavirus; sin embargo, entre los hantavirus identificados en roedores en América, sólo la mitad se ha asociado a enfermedad en humanos. El virus Sin Nombre sigue siendo el hantavirus más importante de Norteamérica, región en la que también se ha notificado un bajo número de casos causados por el virus Bayou (huésped natural Oryzomys palustris) o el virus Black Creek Canal (huésped natural Sigmodon hispidus). En América Central y del Sur el cuadro es más complejo. El virus Andes (huésped natural Oligoryzomys longicaudatus) es el principal patógeno en Chile y Argentina, pero probablemente hay otros hantavirus, incluyendo el virus Oran y el virus Lechiguanas, que causan enfermedad en la región central y noroeste de Argentina, el virus Laguna Negra (huésped natural Calomys laucha) un patógeno reconocido en Paraguay y Bolivia ${ }^{16,17}$ y el virus Juquitiba (huésped natural desconocido) en Brasil. La reciente notificación de 12 casos en Panamá durante 1999 y $2000^{14}$ es de especial interés ya que sugiere la posibilidad de que aún existan enfermedades no reconocidas por hantavirus en humanos y otras especies de hantavirus en regiones tropicales de América Central y América del Sur. El hantavirus identificado en Panamá se ha denominado virus Choclo y se determinó que su huésped natural es Oligoryzomys fulvescens.

Cada uno de los hantavirus mencionados se asocia a una especie de roedor específico, en quien el virus causa una infección crónica, con viremia persistente y asintomática, constituyéndose en el reservorio natural de la infección. Los trabajos presentados aquí por C. Pavletic y A. Spotorno et al. nos entregan valiosa información de las especies de roedores en las que se ha identificado hantavirus en Chile, sus características biológicas, su distribución geográfica y la prevalencia de infección en las poblaciones de roedores. Cinco especies de roedores silvestres de las regiones central y sur de Chile presentaron individuos con reactividad serológica a hantavirus; en dos de ellos, Olygoryzomys longicaudatus y Abrothrix longipilis, se logró determinar la presencia del virus mediante técnicas de biología molecular. El virus identificado en $\boldsymbol{O}$. longicaudatus corresponde genéticamente al virus Andes, que se ha establecido como el principal patógeno para humanos en la región. Aún queda por definir si la reactividad serológica observada en otras especies representa un fenómeno biológico de derrame (infección transitoria de otras especies a partir del reservorio natural en $\boldsymbol{O}$. longicaudatus), o corresponde a verdaderas nuevas especies de hantavirus que han evolucionado para infectar específicamente a estas especies y cuya patogenicidad es aún desconocida.

La identificación de hantavirus, tanto en humanos como en roedores, y el estudio de sus secuencias genéticas para establecer sus similitudes y diferencias, han utilizado todas las herramientas modernas que ofrece la biología y se han caracterizado por su rápido desarrollo ante una infección emergente. ${ }^{2} 18,19$ Galeno et al nos ofrecen en esta revista una perspectiva de las bases biológicas de estos métodos y el resultado de su aplicación durante los brotes ocurridos en diversas regiones de Chile. Se informa aquí también, en forma preliminar, un hallazgo de gran trascendencia mundial, cual es la descripción del primer aislamiento de hantavirus a partir de muestras de un ser humano. Las circunstancias en que se produjo este aislamiento tienen una importante proyección en la comprensión de la patogenia de la infección, en cuanto sugieren la existencia de una viremia antes de que se produzcan la enfermedad y respuesta inmunológica.

El hantavirus se transmite al hombre por inhalación de aerosoles generados a partir de saliva, orina o deposiciones de roedores infectados. Las circunstancias en que esto puede ocurrir son diversas. Sotomayor y Aguilera presentan aquí una descripción de las observaciones epidemiológicas realizadas en Chile por el Departamento de Epidemiología del Ministerio de Salud, así como una completa revisión del sistema de vigilancia establecido en el país, como herramienta fundamental para establecer intervenciones preventivas efectivas. Estudios realizados en Argentina han generado evidencias epidemiológicas y virológicas de transmisión persona 
Emergencia del síndrome cardiopulmonar por hantavirus en las Américas - G. J. Mertz y P. A. Vial C.

a persona del virus Andes (20,21). En Chile no se ha notificado ningún caso de transmisión nosocomial, ni se han documentado casos de transmisión persona a persona, aunque este mecanismo ha sido sugerido en algunos brotes intrafamiliares. ${ }^{13}$ El hecho de que en Chile se haya observado que $30 \%$ de los casos se producen en grupos familares (dos o más miembros de una familia afectados), requiere de estudios que permitan determinar si esto se debe a exposición a una fuente común de infección o bien, a transmisión persona a persona. Estudios de seroprevalencia de hantavirus en diversas regiones de América muestran que entre 1 y 13\% de los individuos de las poblaciones estudiadas presentan anticuerpos contra este virus. Estas observaciones son concordantes con el hallazgo presentado por Sotomayor y Aguilera de infecciones clínicamente leves o asintomáticas, indicando que no todas las infecciones evolucionan hacia SPH.

Nuestro conocimiento de la evolución clínica y la patofisiología de la enfermedad por hantavirus ha progresado significativamente desde que fue reconocida en $1993 .{ }^{22}$ Durante la epidemia de 1993-94 en el Sur-Oeste de E.U.A., investigadores clínicos de la University of New Mexico describieron la importancia de la depresión de la función cardíaca y el shock en los casos severos y fatales. ${ }^{23}$ Estos fenómenos son de importancia en la comprensión de la patogenia de la enfermedad severa y también tienen utilidad como herramienta de diagnóstico, ya que la medición del índice cardíaco, la presión de lecho pulmonar y la resistencia vascular sistémica, ayudan en la diferenciación del shock séptico del producido por la infección por hantavirus. ${ }^{23}$ Consecuentemente, ante la importancia de la disminución de la función cardíaca en la patogenia de la evolución severa o la fatal, se prefiere actualmente denominar la enfermedad como síndrome cardiopulmonar por hantavirus (SCPH).

Las características clínicas de la infección por hantavirus, pueden diferir según la especie de virus que infecta a un individuo. Los virus presentes en Asia y Europa parecen focalizar el mayor daño clínico en el riñón y los presentes en América, en el pulmón y en el corazón. Los trabajos presentados por Navarrete et al, Castillo et al y Tapia et al, nos permiten establecer las características clínicas observadas en los individuos infectados en Chile, sugiriendo que el síndrome clínico observado en esta región tiene mayor compromiso hemorrágico y renal, asociado al compromiso cardiopulmonar observado en Norte América. Al mismo tiempo, es importante destacar que en Chile, en relación a Norte América, se observa que un mayor porcentaje de los casos afecta a menores de 15 años (15\% de los casos). Soza et al nos ofrecen aquí una valiosa descripción de las características clínico-epidemiológicas de 6 casos pediátricos en la IX y X regiones de Chile.

Actualmente no se cuenta con una terapia efectiva y probada contra el SCPH; sin embargo, diversas observaciones recientes indican que existen intervenciones terapéuticas que merecen considerarse para ser incluidas en ensayos clínicos controlados.

El antiviral ribavirina, administrado en forma endovenosa, está siendo evaluado desde 1995 en un ensayo clínico controlado con placebo en E.U.A. y Canadá. El interés por evaluar la ribavirina se basa no sólo en la demostración de que este antiviral tiene actividad in vitro contra el virus, sino también en la demostración de su eficacia. En un estudio prospectivo, doble-ciego, controlado por placebo, efectuado sobre 242 pacientes en China, con infección confirmada por el virus que produce fiebre hemorrágica con síndrome renal, se estableció su eficacia al disminuir la mortalidad y el desarrollo de insuficiencia renal. ${ }^{24}$

Si bien la evaluación de ribavirina endovenosa en el SCPH está en curso, existe preocupación de que el estudio no reclute suficiente número de pacientes para determinar si ella es efectiva; tampoco ha sido posible incorporar un número significativo de pacientes durante la fase de pródromo febril, etapa en la que la ribavirina tendría, teóricamente, la mejor oportunidad de ser efectiva y traducirse en beneficios para el paciente. La evidencia actualmente disponible sugiere que la fase de compromiso cardiopulmonar del SCPH podría ser mediada por respuestas de inmunidad celular y por una "tormenta de citokinas". ${ }^{25}$ Existe entonces interés, por parte de investigadores de numerosos países, incluidos Argentina, Canadá, Chile y E.U.A., en diseñar 
Emergencia del síndrome cardiopulmonar por hantavirus en las Américas - G. J. Mertz y P. A. Vial C.

ensayos clínicos que puedan evaluar terapias con corticosteroides u otras terapias inmunomodulatorias en pacientes en fase cardiopulmonar del SCPH.

La Unidad de Cuidados Intensivos de University of New Mexico Health Sciences Center (UNMHSC) ha usado oxigenación con membrana extra corpórea (extracorporal membrane oxygenation ó ECMO) en 27 pacientes con SCPH severo, en quienes se esperaba que tendrían una evolución fatal si no se trataban. De estos 27 pacientes, 11 fallecieron, uno está aún conectado a ECMO al escribir esta editorial, uno salió recientemente de ECMO y se espera que sobreviva, y 14 han sido dados de alta del hospital (M. Crowley, comunicación personal). Estos resultados son prometedores pero no resulta claro cuán ampliamente puede o debe ser adoptado el uso de ECMO. Sólo un limitado número de centros en E.U.A. y Canadá han utilizado ECMO para el $S C P H, y$ pocos, fuera de la University of New Mexico han tratado más de uno o dos pacientes. Si bien ECMO está disponible en algunos centros de Santiago, la mayoría de los pacientes con $S C P H$ son hospitalizados en centros distantes de aquellos que cuentan con experiencia en ECMO, y el transporte oportuno a Santiago es muy difícil para la mayoría de estos pacientes. Durante un seminario realizado en Temuco, en Marzo del 2000, algunos médicos clínicos chilenos sugirieron una evaluación abierta del uso de contra-pulsación con balón aórtico en un número limitado de pacientes con shock secundario de SCPH.

Investigadores de la University of New Mexico informaron recientemente que los pacienes con SCPH severo o fatal tenían títulos de anticuerpos neutralizantes significativamente menores el día de ingreso al hospital que los títulos observados en aquellos pacientes con enfermedad moderada. ${ }^{26}$ Se han diseñado estudios, por parte de investigadores del ISP de Chile y la Pontificia Universidad Católica de Chile, para evaluar si este fenómeno está también presente en individuos con SCPH causado por el virus Andes en Chile. Si estos resultados son confirmados en SCPH por virus Andes en Chile, se podría considerar el inicio de ensayos terapéuticos con anticuerpos neutralizantes.

La prevención y el manejo ambiental representan actualmente la mejor herramienta de salud pública contra la infección por hantavirus. Pavletic presenta en este número una detallada revisión de las intervenciones efectivas para lograr este objetivo, a la luz de los antecedentes disponibles de la epidemiología de la infección en Chile.

La información entregada en este número de la Revista Chilena de Infectología, mediante trabajos originales, representa un modelo de trabajo científico frente a la emergencia de una infección en una región, caracterizado por un estudio colaborativo entre profesionales de diversas disciplinas, por el esfuerzo de transformar en experiencia y una instancia formativa el trabajo epidemiológico, clínico y de laboratorio, y por la solidez de los resultados que generan conocimientos relevantes a nivel mundial.

\section{BIBLIOGRAFIA}

1.- DUCHIN J S, KOSTER F, PETERS C J et al. Hantavirus pulmonary syndrome: a clinical description of 17 patients with a newly recognized disease. $\mathrm{N}$ Engl J Med 1994; 330 (14): 949-55.

2.- KSIAZEC T G, PETERS C J, ROLLIN P E et al. Identification of a new north american hantavirus that causes acute pulmonary insufficiency. Am $\mathbf{J}$ Trop Med Hyg 1995; 52: 117-23.

3.- CHILDS J E, KSIAZEK T, SPIROPOULOU C F et al. Serologic and genetic identification of Peromyscus maniculatus as the primary rodent reservoir for a new hantavirus in the southwestern United States. J Infect Dis 1994; 169: 1271-80.

4.- YOUNG J, MILLS J, ENRIA D, DOLAN N, KHAN A, KSIAZEK T. New World hantaviruses. Brit Med Bull 1998; 54: 569-73.

5.- HJELLE B, TORREZ-MARTINEZ NORAH, KOSTER F T et al. Epidemiologic linkage of rodent and human hantavirus genomic sequences in case investigations of Hantavirus Pulmonary Syndrome. J Infect Dis 1996; 173: 781-86.

6.- LEVIS S C, BRIGGILER A M, CACASS M. 
Emergence of hantavirus pulmonary syndrome in Argentina (abstr.) Am. J Trop Med Hyg 1995; 53 (suppl): 441.

7.- LOPEZ N, PADULA P, ROSSI C et al. Genetic identification of a new hantavirus causing severe pulmonary syndrome in Argentina. Virology 1996; 220: $223-6$

8.- LOPEZ N, PADULA P, ROSSI C et al. Genetic characterization and phylogeny of Andes virus and variants from Argentina and Chile. Virus Res 1997; 50: 77-84.

9.- LEVIS S, MORZUNOV S, ROWE J et al. Genetic diversity and epidemiology of hantavirus in Argentina. J Infect Dis 1998; 177: 529-38.

10.- ZAPAROLLI M A, IVERSSON L B, ROSA M D et al. Investigation on case contacts of human disease caused by hantavirus in Juquitiba, State of Sao Paulo, Brazil. (abstr.) Am J Trop Med Hyg 1995; 53 (suppl): 439-

11.- DOYLE T, BRYAN R, PETERS C J. Viral Hemorrhagic Fevers and Hantavirus Infections in the Americas. Infect Dis Clin N A 1998; 12: 95-110.

12.- Centers for Diseases Control and Prevention Hantavirus Pulmonary Syndrome-Chile 1997. MMWR 1997; 46: 949-51.

13.- TORO J, VEGA J, KHAN A et al. An outbreak of hantavirus pulmonary syndrome, Chile 1997. Emerg Infect Dis 1998; 4: 667-702.

14.- Centers for Diseases Control and Prevention. Hantavirus Pulmonary Syndrome - Panama 19992000. MMWR 2000; 49 (10): 205-7.

15.- WILLIAMS R J, BRYAN R T, MILLS J N. An outbreak of Hantavirus Pulmonary Syndrome in Western Paraguay. Am J Trop Med Hyg 1997; 57 : 274-82.

16.- JOHNSON A M, BOWEN M D, KSIAZEK T G et al. Laguna Negra virus associated with HPS in Western Paraguay and Bolivia. Virology 1997; 238: 115-27.

17.- ESPINOZA R, VIAL P, NORIEGA L $M$ et al. Hantavirus Pulmonary Syndrome in a Chilean patient with recent travel to Bolivia. Emerg Infect Dis 1998; 4: 93-5.
18.- HJELLE B, JENISON S, TORREZ-MARTINEZ N et al. Rapid and specific detection of Sin Nombre virus antibodies in patients with Hantavirus Pulmonary Syndrome by a strip immunoblot assay suitable for field diagnosis. J Clin Microbiol 1997; 35: 600-8.

19.- ELGH F, LUNDKVIST A, ALEXEYEV A et al. Serological diagnosis of Hantavirus infections by an enzyme-linked immunosorbent assay based on detection of immunoglobulin $\mathrm{G}$ and $\mathrm{M}$ responses to recombinant nucleocapsid proteins of five viral serotypes. J Clin Microbiol 1997; 35:1122-30.

20.- WELLS R, SOSA S, YADON Z et al. An unusual Hantavirus outbreak in Southern Argentina: person to person transmission?. Emerg Infect Dis 1997; 3: 171-4.

21.- PADULA P J, EDELSTEIN A, MIGUEL D L et al. Hantavirus Pulmonary Syndrome outbreak in Argentina: Molecular evidence for person to person transmission of Andes virus. Virology; 1998; 241: 323-30.

22.- ZAKI S R, GREER P, COFFIELD L et al. Hantavirus Pulmonary Syndrome. Pathogenesis of an emerging infectious diseases. Am J Pathol; 1995; 146: 552-79.

23.- HALLIN G, SIMPSON S, CROWELL R et al. Cardiopulmonary manifestations of hantavirus pulmonary syndrome. Crit Care Med 1996; 24 (2): 252-8.

24.- HUGGINS J W, HSIANG C M, COSGRIFF T M et al. Prospective, double-blind, concurrent, placebocontroled clinical trial of intravenous ribavirin therapy of hemorrhagic fever with renal syndrome. J Infect Dis 1991; 164: 1119-27.

25. MERTZ G J, HJELLE B L, WILLIAMS T M, KOSTER F T. Host responses in the Hantavirus Cardiopulmonary Syndrome. In: Saluzzo JF, Dodet $\mathrm{B}$, eds. Factors in the Emergence and Control of Rodent-Borne Viral Diseases. Elsevier, Paris 1999; pp 133-7.

26.- BHARADWAJ M, NOFCHISSY R, GOADE D, KOSTER F, HJELLE B. Humoral immune responses in the hantavirus cardiopulmonary syndrome. J Infect Dis $2000 ; 182: 43-8$. 